\title{
Adaptive Self-regulation: A Process View of Managerial Effectiveness
}

\author{
Anne S. Tsui \\ University of California \\ Susan J. Ashford \\ The University of Michigan
}

\begin{abstract}
This article describes a set of processes involved in attaining managerial effectiveness. These processes are components of an adaptive self-regulation framework. They involve the active management of constituencies' role expectations and performance opinions through standard-setting, discrepancy-detection, and discrepancy-reduction. These processes serve to enhance constituents' opintons of the manager's effectiveness. Several social and contextual factors that either factlitate or inh but managers' self-regulation efforts are identified and hypotheses to guide future empirical research are offered.
\end{abstract}

Organizations, and managers working within them, today face several pressing realities. Organizations are downsizing, restructuring, merging and retooling with striking frequency in response to more turbulent, more competitive and more global marketplaces. Accompanying these changes has been a streamlining of managerial ranks. In the first half decade of the 1980's, 500,000 managerial and professional jobs were eliminated (Buono \& Bowditch, 1989) and this trend is continuing (Cameron, Freeman, \& Mishra, 1991). One consequence of these trends is an intensifying of the complexity of managerial work. Managers are now held responsible for a wider array of activities than before, including making rapid adjustments to external changes. Under such conditions, it may be impossible and, indeed undesirable for organizations to control managers' behaviors using traditional control mechanisms such as job descriptions, standard operating procedures and static performance appraisal systems (Mills, 1983; Slocum \& Sims, 1977). Instead, the processes most needed in the ambiguous and complex situations just described would seem to be those of self-regulation and self-control on the part of managers themselves. Managers skilled in self-regulation can respond to the complexity and dynamic pace of their immediate environment in a timely fashion. In these situations, selfregulation by managers is not only a substitute for other sources of structure

Direct all correspondence to Anne S Tsui, Unıversıty of Calıfornı, Graduate School of Management, Irvine, CA 92717

Copyright $\stackrel{\odot}{1994}$ by JAI Press Inc. 0149-2063 
(Mills, 1983; Manz \& Sims, 1980), it is a necessity if the organization is to survive and to prosper. By emphasizing the nature of the contemporary setting as an important context for managerial self-regulation, we are not implying that this process is not relevant or important for managers in different time periods. Rather, we are suggesting that the unprecedented pace of changes in the current external environment heightens the need for rapid adaptation by managers.

Two additional enduring realities of managerial work further suggest the importance and relevance of self-regulation at the managerial levels. First, managers operate within a social structure consisting of multiple constituencies or stakeholders (e.g., peers, subordinates, superiors, and customers) each of whom has his or her own expectations of and reactions to the manager (Salancik, Calder, Rowland, Leblebici, \& Conway, 1975). Given that managers are dependent on these constituents to some degree, their behaviors have reputational consequences (Tsui, 1984a; 1984b), they cause key constituents to want to give or withhold important resources such as information and cooperation. As such, how managers are perceived and evaluated by these constituents is important for managerial success. Second, as managers move up the organizational hierarchy, it takes longer and longer to obtain task feed back on their performance (Jaques, 1961). Thus, managers' primary source of feedback may be the subjective opinions of these key constituents. These additional realities suggest that self-regulation by managers is in part a social process involving attempts to understand and influence the opinions of various relevant constituents in order to achieve organizational goals.

In this article we present a model of managerial self-regulation with three intended contributions to the existing literature. First, we move beyond current formulations of self-management (Manz, 1986; Manz \& Sims, 1980) by emphasizing the adaptive aspects of the self-management process. In this model, we specify how managers can benefit from seeking out, understanding and managing the expectations and evaluations of key constituents. Second, we discuss personal and context factors that facilitate managerial self-regulation. That is, if organizations do face new realities and are more dependent on the self-regulation of managers, what personal and context characteristics facilitate or hinder managers from carrying out this process? Do organızations retain control systems, for example, that may be antithetical to self-regulation? Finally, with this model we add to the literature on managerial effectiveness by specifying the processes involved in achieving effectiveness as a manager. Though a shift from the study of person to process predictors of effectiveness was strongly advocated by Campbell, Dunnette, Lawler, and Weick (1970), only limited subsequent theoretical or empirical attention has been given to the specific processes that managers use to improve their effectiveness. Most previous process research has focused on defining the behaviors in which managers engage (c.f. Luthans, 1988; Morse \& Wagner, 1978) and cataloguing those behaviors into a series of underlying dimensions or roles (cf. Minzberg, 1973). That research, however, did not focus on the sequence, steps, or processes in which managers engage to facilitate effectiveness. Further, empirical tests of these behavioral prescriptions suggest that different roles were more or less 
important for different managers at different levels in the organization (Morse \& Wagner, 1978) and for different jobs (Stewart, 1982). These observations suggest that a process more fundamental than role fulfillment may underlie managerial effectiveness, a process that includes determining the relative importance (or even the relevance) of specific roles in a given situation. In other words, while previous research has identified specific roles for managers, the focus of the current model is on the processes that help managers to determine which roles are particularly relevant in their specific situations.

Consistent with this view, Kenny and Zaccaro (1983) have suggested that effectiveness may reflect an ability to perceive the needs and goals of various constituencies and to adjust personal approaches accordingly rather than any particular personality trait or behavior. The importance of adjusting personal approaches for effectiveness is a central thesis in the path goal theory of leadership (House, 1971) and the multiple constituency approach to managerial effectiveness (Tsui, 1984a; 1984b). Similarly, recent research on influence tactics also found those who use a variety of tactics, according to the needs of the situation or the nature of the influence target, tended to be more effective than those who rely consistently on one single tactic (Kipnis, Schmidt, \& Wilkinson, 1980).

The adaptive self-regulation process briefly described above focuses on the effectiveness of the manager as defined by the relevant constituencies in the social structure. Tsui $(1984 \mathrm{a} ; 1984 \mathrm{~b})$ referred to this type of effectiveness as reputational effectiveness which, she found, is different from but important for managerial success as indicated by merit increases and promotions. The current self-regulation framework focuses on manager's reputational effectiveness as an outcome of the adaptive self-regulation process. In other words, the fundamental thesis is that those managers who engage in the behaviors as specified in the self-regulation process will be judged to the more effective by constituencies than will managers who do not.

We will first describe the core elements of the self-regulation process. Following that, we will analyze the factors that may influence self-regulation. These factors include personal and interpersonal variables as well as contextual factors such as certain job and organizational characteristics.

\section{An Adaptive Self-Regulation Model}

The concept of self-regulation or self-control originated in the field of psychological therapy (c.f. Kanfer, 1971; Kanfer \& Karoly, 1972). The therapeutic question was how to help people to help themselves. The specific self-control question was how to get people, in light of a more attractive alternative (e.g., a hot fudge sundae), to choose a less attractive option (e.g., carrot sticks). These researchers proposed that individuals could exert selfcontrol by complying with the following close looped self-regulation process: set a goal, self-monitor behavior in light of that goal (observing instances of compliance with and deviation from the goal), self-evaluate and self-consequate (self-reward or punish) (Kanfer \& Karoly, 1972). 
Organizational researchers have applied this model to organizations under the label behavioral self-management (Andrasik \& Heimberg, 1982; Luthans \& Davis, 1979) and applied it to such behaviors as controlling time spent on the phone and processing paperwork. Self-management (cf. Andrasik \& Heimberg, 1982; Luthans \& Davis, 1979; Manz \& Sims, 1980) generally consists of "a set of strategies that facilitate behaviors that serve to reduce deviations from higher level reference values." (Manz, 1986, p. 588). Thus, selfmanagement by an individual involves using self-goal-setting, self-observation, self-reward and self-punishment to control behaviors. Manz (1986) suggested that this literature could be improved by considering the source of higher level reference values and including consideration of values that are externally imposed as well as those personally chosen by the individual. We concur with his view but propose to extend the self-management process further by: (1) applying self-regulation notions to a broader range of behaviors; and (2) taking into account the realities of organizational settings by tracking the implications of those realities for the managerial self-regulation process.

Previous self-management research has focused narrowly on how individuals might control discrete, specific, objectively measurable behaviors (e.g., answering telephones or filling out expense reports correctly) aimed at achieving specific goals (Luthans \& Davis, 1979). In organizations, however, the foci of self-regulation are often much more ambiguous in nature and may Include a manager's style, approachability, and leadership, in addition to specific task goals. These attributes capture broad behavioral patterns which, while clearly important to a manager's effectiveness, often cannot be measured objectively by the manager in order to apply self-rewards or punishments. Indeed, perhaps the only measure of any importance for these attributes lies in the subjective judgments of the manager's constituencies.

The self-management literature treats individuals as if they were isolated systems, whose sole tasks are those of observing their own behavior, setting up cues and reinforcing and punishing themselves (Mahoney \& Arnkoff, 1978). While this perspective is consistent with the therapeutic contexts from which self-management ideas were derived, the situation is more complicated in organizations. Because managers operate within a social structure and in a context with both formal and informal control and reward structures, they must incorporate the views of others in their self-regulation efforts. Managers failing to incorporate others' views run the risk of being "selected out" (i.e., being fired, transferred, or not given promotions) by the organization's larger control system. Thus, while typical self-management treatments portray the process as an intrapersonal one, in organizations and especially for managers, it needs to be extended to the interpersonal arena as well. A manager's self-regulation, by necessity, needs to incorporate the input of others. This argument carries Manz's (1986) and Mills' (1983) logic one step further. They both proposed that the organization's control system affects the individual's control system. We argue that individual managers, to be effective or successful, must bring about a fit between their own control system and that of the organization. We propose that this fit is accomplished through the an adaptive self-regulatory process. 


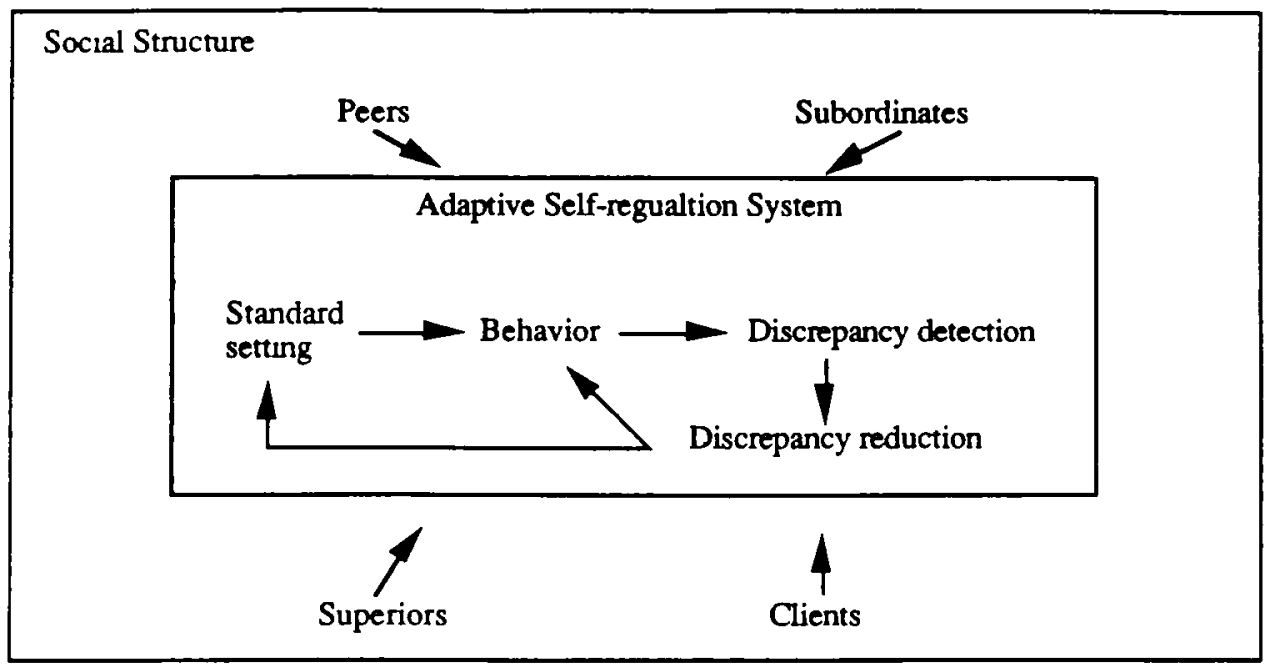

Figure 1. An Adaptive Self-regulation Model

This process and the context in which it occurs are presented in Figure 1. The elements of this model are discussed below.

\section{Standard-Setting}

The standards that managers adopt for their own behavior include both specific roles and strategies to perform in these roles. Normally, standard setting is straightforward - a manager's superior prescribes and explicitly communicates a set of standards to be met. However, this process is complicated by several factors. First, the roles prescribed by the formal control system (i.e., superiors) are seldom complete. Occasionally superiors might intentionally leave some roles unspecified to allow the manager some autonomy. At other times the information necessary to set a specific goal may be unavailable due to a poor control system (Chase, 1990) or due to the dynamic nature of the organizational environment. Second, a range of others besides the manager's superior may prescribe roles for the manager. These constituents may have expectations for specific roles, behaviors or outputs for the manager. These constituents, however, may express their expectations less directly than will the superior. With these constituents, managers may be forced to infer standards from a host of direct or indirect cues. Inferences from such cues may only partially mirror constituents' actual demands. Third, managers may also have their own agendas based on personal goals or political aspirations (Manz, 1986; Stewart, 1979). Thus, they are a constituency for themselves. Manz (1986) defines the essence of self-leadership as the individual setting his or her own goals. An adaptive perspective suggests, however, that in the context of a social structure, these self-goals must be reconciled with others' demands (Gabarro 
\& Kotter, 1980; Kotter, 1982). That is, the manager's own agenda may be either consistent or conflictual with each of the constituent's expectations. Similarly, standard-setting is complicated by the fact that constituents may or may not agree in their expectations for the target manager. As pointed out by Kahn, Wolfe, Quinn, Snoek, and Rosenthal (1964), these conflicts produce much ambiguity and complexity for the manager regarding which standards to adopt.

Each of these variables (the nature of constituent expectations, the communication of these expectations, the clarity of a manager's own agenda, and the degree of demand consensus across constituencies) affects the standardsetting process. Initial standards may arise from an individual's values or desires by a process of self-leadership (Manz, 1986), through direct communication as mentioned above, and/or from higher level standards in the individual's goal hierarchy (Taylor, Fisher, \& Ilgen, 1984). Standard setting in the self-regulation system, however, is an adaptive dynamic process. Initial standards are revised to adapt to the demands of the social structure. Changes in the requirements of the formal control system and the nature of the social structure may suggest possible changes in the manager's goals and standards. Adaptive self-regulation involves the modification of initial standards, over time, using the discrepancydetection and reduction process.

\section{Discrepancy Detection}

Managers must minimize or control two types of discrepancies. First, discrepancies may occur between what the manager and various constituents thınk are the appropriate roles or performance standards for the manager. Second, discrepancies may occur also between how the manager and various constituents evaluate the manager's actual performance on the job.

To detect discrepancies between their own standards and standards held by their constituencies, managers need information regarding constituent expectations. Without this knowledge, managers may pursue goals that are not valued by their constituents. Presumably such pursuits will be costly in some organizations' environments, where satisfying multiple constituencies may be important and where constituents use their own expectations as the yardstick in judging the effectiveness of a manager (Tsui, 1984a). If the managers themselves are trying to minimize discrepancies regarding a quite different yardstick, reputational effectiveness will not occur.

Therefore, in most situations, the more managers know regarding constituents' expectations, the greater their potential to produce behaviors congruent with those demands and/or to take steps to change constituent expectations. One direct method of gaining this information is by explicitly and actively soliciting it from constituents. Given the complexity of the social structure, managers will have a greater potential to detect discrepancies when they engage in a broad-based search. By so doing, they will reveal potential discrepancies between constituencies as well as between each constituency and their own agendas. This action is consistent with the idea of discrepancy production in the social cognition theory of motivation and self-regulation (Wood \& Bandura, 1989). ${ }^{2}$ 
Clearly, the most difficult situation managers face is that of mutually exclusive demands-when compliance with one constituency's demands makes compliance with another's impossible or extremely difficult. The negative effects of role conflict on effectiveness and morale are well documented (Gross, Mason, \& McEachern, 1958; Kahn et al., 1964). Less well known is how managers actually resolve the conflict inherent in mutually exclusive demands. Managers inevitably need to make trade-offs, intentional or not. How they make such trade-offs will be discussed in the section on discrepancy reduction. The ability to make such trade-offs, however, assumes that the discrepant demands have been perceived accurately. This ability depends in large part on the extent and nature of information search.

The second discrepancy that may occur is that between the managers' behavior and the standard(s) they have adopted. To detect such discrepancies, managers need feedback (Carver \& Scheier, 1981; Powers, 1973). Managers can provide self-feedback by observing their own behavior and the results of their actions and judging whether or not they are "on target" relative to the standard (Andrasik \& Heimberg, 1982). However, given the social nature of effectiveness (i.e., defined at least in part from the perspectives of multiple constituencies), it is equally, if not more, important for managers to know how their behavior is perceived and evaluated by others. Informal opinions held by various constituencies regarding the ongoing work behavior and performance of the manager are important data for discrepancy detection.

Traditionally, the feedback literature focused on the feedback given directly to individuals (cf. Ilgen, Fisher, \& Taylor, 1979), whether given in an annual performance review, a peer review, or informal conversations with others. In most organizations, however, the amount of feedback received in this manner is insufficient for on-going self-regulation. For example, a management association survey conducted in 1984 found that seventy-five percent of organizations offer formal performance reviews only annually. Informal feedback from superiors and peers is also typically constrained. Supervisors (Fisher, 1979; Ilgen \& Knowlton, 1980) and others (Larson, 1986; Tesser \& Rosen, 1975) are often reluctant to give negative feedback, and even the flow of positive feedback can be constricted (Blumberg, 1972; Felson, 1980). These findings suggest that managers, particularly poor performing ones, do not receive enough spontaneous feedback to regulate their behavior. Fortunately, the work environment provides a wealth of feedback cues beyond those conveyed directly to the manager (Ashford \& Cummings, 1983; Herold \& Parsons, 1985). For example, managers might attend to events that happen to other managers but not to them, they may compare their successes with those of their peers, and/or they may pay close attention to how others act toward them (Ashford \& Cummings, 1983). Managers might also generate feedback by asking various individuals directly for their assessments of the behavior in question. Ashford and Cummings (1983) argued that individuals who seek feedback more frequently should perform better in their jobs. In support, Ashford and Tsui (1991) found that active feedback seekıng was related to accuracy in detecting discrepancies as well as favorable evaluation of the managers' overall effectiveness by superior, subordinates, and peers. 
One variable that may affect managers' success at discrepancy detection is the acumen with which they construe their constituency set and their flexibility in reconstruing this set as time and conditions change. Some managers might define this set quite narrowly (e.g., superior only) while others might include not only the three most obvious constituencies (superiors, peers, and subordinates) but other more distal constituencies as well (e.g., other organizational "higher-ups," clients or customers, or managers in other groups). Research on networking suggests the importance of construing one's relevant constituent group broadly (Kotter, 1982). It is also possible, however, that some managers may construe this set too broadly, spending unnecessary time and effort on irrelevant constituents. Beyond mapping the initial constituent group, managers also may need to reconfigure their thinking about this group over time. For example, as managers move up in the organization, new constituencies may become relevant and others less so. Failure to identify relevant constituencies accurately (e.g., those that have stake in the manager's performance) may produce less successful self-regulation as managers may pursue goals not valued by their important constituencies.

The above discussion suggest two hypotheses regarding discrepancy detection.

H1. Managers who engage in discrepancy detectton (i.e., seeking information on expectations and informal performance opinions from constituents) will be more effective than managers who do not engage in this activity.

H2. Managers who incorporate a broad range of relevant constituencies in their discrepancy detection will be more effective than managers who construe their constituent set narrowly.

The active seeking of expectation and feedback information from constituents may affect a manager's reputational effectiveness in two ways. The first is based on the instrumental value of information on expectation and performance. Managers who seek information and feedback actively have a greater chance of knowing their constituent's expeciations and opinions with some degree of accuracy and, assuming some actions are taken to meet or manage those opinions (actions to be described below), will be more effective. The second means by which active seeking affects reputational effectiveness is through impression-management. Managers may enjoy a boost to their image from being seen as interested in constituent opinions. Thus, independent of the actions managers take to respond to constituent opinions, the simple act of seekıng information and feedback may give managers an impression management advantage. These two logics underlie Hypothesis 1.

The relationship of feedback seeking to effectiveness, however, is not straight-forward. Feedback is a qualitatively different type of information than that defining standards. It is evaluative information, it directly references the self, and thus is inherently affective in nature (Ashford \& Cummings, 1983). 
These attributes suggest that individuals may not be completely rational in their seeking behavior when feedback is the information in question. In particular, Ashford (1986) and others (Jones \& Gerard, 1967; Brickman \& Bulman, 1977) have argued that individuals are conflicted about feedback. They want it because it allows them to correct errors and attain goals, but they are also motivated to maintain favorable views of themselves and thus might avoid feedback that might potentially hurt their self-concept. This tension will affect particularly how individuals handle what they believe will be negative feedback. Managers may avoid negative feedback to maintain their self-esteem (Janis \& Mann, 1977; Miller, 1976). However, because it points out where a manager's behavior is "off track" with respect to his or her goals or standards, negative feedback is most important for performance correction (cf. Ashford \& Cummings, 1985). Several laboratory studies provided evidence on this tension. For example, studies have shown that individuals will seek more difficult tasks, risking more negative feedback, for their diagnostic value (Trope, 1975; Zuckerman, Brown, Fox, Lathin, \& Minasian, 1979). Other evidence suggests that people will avoid such feedback to preserve their self-esteem (Willerman, Lewitt, \& Tellegen, 1960). In organizational settings, individuals may realize that there are costs to both holding an inaccurate self view and exposing weakness. Though individuals may be reluctant to do so, there is intrumental value to seeking out negative feedback in organizations. A recent field study (Ashford \& Tsui, 1991) found managers to seek equal amounts of negative and positive feedback from all sources. However, negative feedback seeking had a positive relationship while positive feedback seeking had a negative relationship with the effectiveness of the manager. The study also found that the seeking of negative feedback was related to an accuracy measure of self view. Based on the diagnostic and the impression management values of negative feedback seeking, the following hypothesis is offered.

H3. The relationship between active feedback seeking, especially the seeking of negative feedback, and reputational effectiveness will be mediated by: (1) accurate knowledge of discrepancies; and (2) the favorableness of the manager's image. There will be neither a direct nor a mediated relationship between the seeking of positive feedback and reputational effectiveness.

The description of adaptive self-regulation to this point seems to assume a high level of rationality in both the cognitive and behavioral processes of the manager. The decision-making literature has shown that such rationality assumptions are not always warranted (cf. Mintzberg, Raisinghanı, \& Theoret, 1976; Nutt, 1984). Thus, we might expect some deviations from rationality in adjusting to the surrounding social structure. For example, some managers might fail to use the information they collect, while others might decide on a course of action and only then seek feedback that is consistent with their chosen course. However, these "irrational" behaviors are not inconsistent with the basic premises of adaptıve self-regulation. "Irratıonal" feedback-seeking will not lead 
to successful adaptation and, consequently, will result in lower reputational effectiveness. Furthermore, even when managers accurately recognize discrepancies, reputational effectiveness will not follow without appropriate discrepancy-reduction actions. A variety of such discrepancy-reduction strategies are described below.

\section{Discrepancy Reduction}

Knowledge of discrepancies alone is not sufficient to attain reputational effectiveness. While this knowledge enables the manager to take actions toward discrepancy-reduction, managers also must engage in a discrepancy reduction process in order to attain effectiveness. Control theory portrays discrepancy reduction as a relatively straightforward process: a detected discrepancy motivates a person to alter his or her behavior to reduce it (Carver \& Scheier, 1981). For example, if visual feedback tells the driver that the car is going off the road, he or she turns the wheel to reduce the discrepancy between this reality and the goal of keeping the car on the road. At lower levels of the goal hierarchy, this discrepancy-reducing maneuver is thought to be relative automatic (Carver \& Scheier, 1981). In a managerial context, however, the discrepancy-reduction process is probably far more complex, involving a large number of possible responses. Kahn et al.'s (1964) early research on the role process provided some initial insights into potential strategies for resolving role conflicts. Research since this work, however, has focused almost exclusively on the simple relationships between role conflict and various outcomes such as performance, stress and satisfaction (see Fisher \& Gitelson, 1983; Jackson \& Schuler, 1985 for reviews). The medrating responses that individuals might undertake in light of role conflict have been relatively understudied. Drawing on role conflict and related literature, we identified two broad classes of responses: effectiveness-oriented strategies aimed at actually reducing the discrepancy detected and esteem-maintenance strategies aimed primarily at defending the manager's ego and self-esteem.

Effectiveness-oriented strategles. There are at least five ways to reduce the gap between standards and behaviors for attaining those standards. First, as Gross et al. (1958) suggested, managers might comply by altering their behavior, just as the driver did in the driving example above. Thus, managers might change their style of responding to subordinates' requests so that their behavior is more congruent with their goal of being a humanistic supervisor or they might start including peers in their informational meetings if their goal is to be seen as a team player. There are a multitude of small and large adjustments managers might make to bring their behavior more in line with the performance standards they hope to attain (Kahn et al., 1964). The basic objective is to comply by changing behavior to meet the standards. However, compliance is not the only strategy available to the manager for discrepancy reduction. Extensive use of this strategy may in fact lead to ineffectiveness. As implied by Staw and Ross (1980), managers who appear to modify their behavior or courses of action frequently are likely to be viewed as weak or as lacking strong vision. These managers, appearing to be "too eager to please," may not be seen as effective. 
A second strategy to reduce discrepancies occurs when managers attempt to influence constituents to change their expectations, without the manager changing his or her behavior (Kahn et al., 1964). Thus, managers detecting a discrepancy between their individualistic behavior and a constituent's standard of team play, for example, might attempt to influence that constituent to see the goals of team play and individualism in a different light (e.g., team play as less attractive). The manager's behavior remains the same, but the constituent's performance expectation changes, thereby reducing the discrepancy and enhancing reputational effectiveness. In this strategy the manager attempts to bring others' expectations in line with his or her own agenda.

A third discrepancy-reducing strategy that managers might use is to get constituents to alter their opinions of the manager's performance or behaviors. Thus, if the manager can influence the constituent to see that the manager's behavior is actually consistent with team play (in the previous example), then there will be no discrepancy to reduce. In this case, the manager's behavior and the standard remain the same but the evaluation of the behavior is altered. This adaptive strategy is similar to "manipulation of audience beliefs," identified by Tetlock and Manstead (1985). It is one of several methods that individuals might use to promote a favorable image to the public. Previous theorizing about the role conflict process has not considered this tactic.

A fourth strategy is also derived from the ideas in Gross et al. (1958). In this strategy, managers follow their pre-specified courses of action and explain the reason for their actions to their constituents. These managers have a strong belief in what is the best course of action for the unit or the organization and are willing to act contrary to others' demands or expectations. This does not mean that they are not sensitive to others' needs or opinions. They just do not blindly comply and they are not afraid to alienate people who disagree with them. Effective managers might mitigate the costs of this strategy by offering a social account (Bies, 1987) that provides a rationale for their actions. The use of this strategy enhances the manager's effectiveness only when he or she knows which constituents' expectations are not being met and attempts to influence these constituents by explaining the reasons for their actions. In this strategy, neither the behavior nor the expectations are altered. The discrepancy still may exist but an effort is made to increase the constituent's understanding, if not acceptance, of the manager's actions. We expect that this strategy will be more effective over time if events subsequent to its use show that the manager was correct in his or her actions. Continued use of this strategy when the manager is consistently wrong in his or her actions and decisions should not result in enhanced effectiveness perceptions.

A fifth strategy involves manager's attempts to alter their constituent set in some way so as to create constituent demands with which the manager's behavior is consistent. This strategy is similar to the fourth strategy described above because it does not involve reducing the discrepancy. Rather, managers bring about a more desirable situation by adding new and powerful constituents to their constituent set or by eliminating those constituents with the most 
onerous expectations. Just as organizations can alter their constituency set by changing their product offerings, geographic regions served, and so forth (Zammuto, 1984); so individuals can create changes in theirs. Thus, individualistic managers may find powerful mentors (who highly value individualism) to add to their constituent sets. Alternatively, they might request special assignments in which they work alone, thereby eliminating peers as a constituency. In this strategy, the behavior remains the same, but the makeup of the constituent group is altered so that the manager's behavior is consistent with the resulting expectations of the constituents. At the extreme, managers can change positions or leave their companies altogether, thereby totally changing their constituency set. As March and Simon (1958, p. 95) observed, an organizational participant has a tendency to "select his group membership so as to keep at a low level the conflict imposed by differences in the demands made upon him." One way to select group membership is to alter constituency set through job transfers. Though Kahn et al. (1964) began to get at this tactic in their discussion of attempts to reject the role sender, we mean more by this tactic than simple rejection. For example, the role set could be altered by addition as well.

The above array of discrepancy-reduction strategies clearly suggests that managers are not seen as totally other-dependent, searching for others' opinions so that they can change their behavior accordingly. Rather, we propose that effective managers search for others' opinions to obtain valuable information. They might then choose to use this information in a variety of ways, including influencing constituents to alter their opinions, dropping a constituent from the constituent set, or changing their own behavior. We argue that managers who know their constituents' expectations and attempt to account for whatever discrepancies they detect will enjoy greater reputational effectiveness than managers who are oblivious to these processes.

Esteem-oriented strategles. The five discrepancy-reduction strategies highlighted above are all aimed at attaining effectiveness. A second set of discrepancy-reduction strategies are aimed at maintaining the manager's selfesteem. These strategies reduce discrepancies in the manager's mind only (and thereby maintain his or her self-esteem). The actual discrepancy, however, is not altered and thus reputational effectiveness should not result. One example of such a strategy is to distort the available feedback so that it confirms the success of the manager's goal-related efforts (Taylor et al., 1984). While this strategy reduces the discrepancy as perceived by the manager, constituents' evaluation of the manager is not altered. Thus, this strategy will not increase effectiveness in the long run. Kahn et al. (1964, p. 84) referred to such distortion as a "defense mechanism" and noted that the inevitable outcome of its use is that the focal manager's behavior becomes less and less adaptive. This strategy may have some short-run benefits, however, as it enhances managers' beliefs regarding their potential to attain the standard and may thereby allow them to persist in short-run efforts (Carver \& Scheier, 1981).

A second esteem-oriented discrepancy-reducing strategy is that of simply lowering one's standards. If managers hold particular standards and receive (or 
sense) feedback that they are not meeting those standards, lowering their standards is one way to reduce the discrepancy. By following this strategy, they can view themselves as meeting their now reduced standards. Campion and Lord (1982) found, for example, that repeated negative feedback led students to lower their standards. While this strategy would again reduce the discrepancy in the manager's mind, because it does not involve changing actual behavior, it leaves the actual discrepancy unresolved. Consequently, reputational effectiveness with the constituency involved also should not occur.

A third class of esteem-maintenance strategies is that of avoidance (Gross et al., 1958; Moos \& Billings, 1982), or disengagement (Hyland, 1987). Kahn et al. (1964) suggested that in this response, managers can either behaviorally avoid the source of discrepant feedback or cognitively avoid thinking about discrepant feedback by disengaging. While this strategy may function as a selfprotective esteem-maintenance device, it clearly has no effect on the actual discrepancy.

The relationships of effectiveness-oriented and esteem-oriented discrepancy-reduction strategies to reputational effectiveness are hypothesized below:

H4. Managers who engage in effectiveness-oriented discrepancyreduction strategies will be more effective than managers who engage primarily in esteem-oriented responses.

\section{Factors Influencing Self-Regulation}

Our theoretical analysis to this point contains two implicit assumptions. First, that all managers are motivated and capable of engaging in the various self-regulation activities. Second, that self-regulation is desirable and possible in all organizational settings. These two assumptions may not be reasonable. Below, we examine the primary personal and contextual factors that may influence the extent of and the manner in which self-regulation activities may be carried out by different managers.

\section{Personal and Interpersonal Factors Influencing Adaptive Self-Regulation}

The sources of motivation for self-regulation as presented here are both internal and external. One internal source of motivation is the managers' belief in their personal efficacy (Bandura, 1988). Managers with high self-efficacy have a belief in their capability to control events and to achieve goals. These individuals will exert more effort and persist longer to master the challenge than those with a lower level of self-efficacy. Self-efficacy also influences aspiration. The stronger the perceived self-efficacy, the higher the goals people set for themselves, the greater their willingness to seek feedback on their performance, and the higher likelihood of selecting effectiveness-oriented discrepancy reduction strategies.

Carver and Scheier (1981) discussed the role of efficacy expectations in the self-control process. They argued that individual's efficacy expectations 
regarding the ability to meet the standard is the prime determinant of an individual's response to a perceived discrepancy. Their analysis suggest that if the probability is quite low, individuals will likely use what we have labeled esteem-oriented strategies - they will reduce their goals, avoid thinking about the discrepancy or distort feedback indicating a discrepancy. If the probability is quite high, however, individuals will continue working toward the standard without any change in their goal-directed behaviors (Carver \& Scheier, 1981, Taylor et al., 1984). Expectancies in the middle range should result in the use of effectiveness-oriented discrepancy reduction strategies. This argument suggests:

H5. Managers with strong self-efficacy perceptions will be more likely to engage in active feedback seeking and to use effectivenessoriented strategies to reduce detected discrepancies than with those with weak self-efficacy perceptions.

A second individual differences variable that may influence self-regulation tendency is self-esteem. It has been found that individuals with low self-esteem tended to avoid negatıve feedback (e.g., Miller, 1976; Willerman et al., 1960). By avoiding negative feedback, these individuals will be less likely to detect discrepancies. Even if discrepancies were brought to their attention, they would tend to choose responses focused on maintaining or enhancing their self-esteem. Thus the following hypothesis:

H6. Managers with low self-esteem will be more likely to seek posituve feedback, to avold negatlve feedback, and to use esteemoriented discrepancy reduction strategies than will managers with high self-esteem

We have argued that impression management plays a key role in the selfregulation-reputational effectiveness relationship. A third personal factor, individual differences in self-monitoring (Snyder, 1979) captures how individual differences in impression management sensitivity and ability may affect the selfregulation process. Individuals high in self-monitoring are thought to be particularly sensitive to the cues for appropriate behavior given off by others and especially able to adjust their behavior appropriately (Snyder, 1979). This sensitivity almost definitionally implies an active participation in the adaptive self-regulation process. Researchers have proposed that self-monitoring is made up of three components: social stage presence, other-directedness and expressive self-control (Briggs, Cheek, \& Buss, 1980; Lennox \& Wolfe, 1984). While Snyder and Gangestad (1986) presented evidence for the connection of each of these components to a general latent self-monitoring construct, even at the level of individual factors, it seems likely that individuals who are high on each should be more effective self-regulators. The high self monitoring manager actively tunes into cues regarding constituents' expectations and thus readily detects discrepancies in expectations and evaluations (other-directedness). Further, the 
high self-monitors' ability to adjust his or her behavior to respond to cues suggest that managers high on this trait may be more likely to engage in effectivenessoriented strategies, and in particular may be more likely to adjust their behavior to meet constituent's demands as their predominant discrepancy-reduction strategy (social stages presence and expressive self-control). This strategy may come naturally and may be used almost without conscious consideration by these able "chameleons" who, according to Snyder (1979, p. 93), actively attempt to "construct a pattern of social behavior appropriate to that particular context." This understanding of self-monitoring suggests:

H7. Managers high in self-monitoring will be more active in adaptive self regulation and more likely to use a behavioral adaptation discrepancy-reduction strategy than managers low in self-monitoring.

Several factors should influence a manager's choice of specific discrepancy reductıon strategies. For example, Gross et al. (1958) proposed three variables that govern which resolution strategy is chosen. These variables are, legitimacy: whether or not the incumbent believes that the individuals making the claim have a right to expect conformance; sanctions: whether those holding the expectation can sanction the incumbent; and personal orientation: the incumbent's tendency to place greater weight on legitimacy concerns, sanctions or both. The higher the legitimacy of the expectation and the ability to sanction, the more likely it is that the role incumbent (focal manager in our language) will conform to the expectation. The role incumbent's personal orientation will determine which of two conflicting expectations he or she will respond to, assuming that the expectations themselves differ on their legitimacy and attached sanctions.

The distinction drawn by Gross et al. (1958) suggest that the first interpersonal factor that may affect managers' adaptive self-regulation is the power relationship between the focal manager and the constituent. We would expect compliance to be used as a discrepancy-reduction strategy more frequently when the constituent is the focal manager's superior rather than his/ her subordinate. Similarly, all other things being equal, we would expect an "act and explain" (i.e., letting the discrepancy stand) strategy to be used more with subordinates than with superiors. These choices would seem consistent with the differences in legitimate power between the focal manager and the constituent in the two cases. With peers, the focal manager's tendency to use either a compliance or noncompliance strategy should depend on their peers' power relative to their own. This power might be based on the peers' centrality or criticality in the work flow (Hıckson, Hinings, Lee, Schneck, \& Pennıngs, 1971), their referent power and/or their expert power. The greater the power of the peer relative to the focal manager, the greater the tendency to comply and the less the tendency to ignore the discrepancy. The general point is that some strategies may be used more often with some constituencies than with others. Managers may assertively correct subordinates' expectations. They may accommodate a superior's standards, or may compromise with those of his/ 
her peers. This analysis is consistent with research on influence tactics which found that managers employ different influence strategies with superiors, subordinates, or peers (Kipnis et al., 1980). Power relationship may influence not only the choice of discrepancy reduction strategies, but also the seeking of information on expectations and feedback on performance. Managers would be more motivated to seek such information from superiors than from peers or subordinates. Ashford and Tsui (1991) confirmed such a tendency. The following two hypotheses capture the effect of power on self-regulation.

H8. Managers will be more active in seeking feedback from the more powerful than the less powerful constituencies.

H9. Managers will use different discrepancy reduction strategles with different constituencies, depending on their power relationship to the constituenctes.

A second interpersonal factor influencing a manager's choice of discrepancy-reduction strategies is the manager's orientation towards conflict situations. Thomas (1976) identified five orientations; competition, collaboration, sharing, avoidance and accommodation. He argued that while some individuals may move from one orientation to another, most individuals tend to rely on some modes more heavily than others, either due to temperament or practice. A manager with an accommodation orientation would tend to use compliance discrepancy reduction strategies. Those with a competition orientation would tend to act as they want, ignoring the discrepancy. Managers with a collaboration or a sharing (compromising) orientation may attempt to influence their constituents' expectations or to get constituents to change their perceptions of the behavior in question. Managers with an avoidance orientation may either do nothing or retreat to an esteem-maintenance strategy rather than attempt to resolve the discrepancy directly. The following proposition captures these differences:

H10. Managers differing in their conflict orientation will differ in their choice of discrepancy-reduction strategies. Specifically:

1 managers high in accommodation ortentation would tend to use the compliance strategy,

2. managers high in competition orientation would tend to use the act and explain strategy, and

3. managers high in collaboration or compromising ortentation would tend to use the two constituent influence strategies.

A final factor that may influence the extent and success of self-regulation is the degree of interpersonal trust between managers and their constituents. O'Reilly and Anderson (1980) reported a study in which they found various aspects of feedback to be differentially related to performance and satisfaction 
under conditions of high and low trust. Presumably, trust would influence both the extent and the quality of feedback and communication between two individuals. All else being equal, it is expected that managers will seek negative feedback using a direct seeking strategy from constituents whom they trust more often than from those whom they do not trust. Similarly, constituents who trust the manager will give more honest feedback than will constituents whom have a lower level of trust in the manager. Thus, seeking will lead to more accurate information under a high than a low interpersonal trust condition. This analysis suggests the following hypotheses:

H11. Managers will be active in seeking negative feedback and more likely to use the direct method of seeking from constituents whom they trust than from those they do not trust.

H12. Manager will have more accurate knowledge of theur constituents' expectations and opinions of their performance when there is a high rather than a low level of interpersonal trust between them and their constttuents.

\section{Contextual Influences on Adaptive Self-regulation}

The above discussion emphasizes a number of personal and interpersonal factors that may influence the self-regulation process. We now suggest several job and organizational variables that may systematically affect the selfregulation process as well. These contextual variables may be considered as external sources of motivation for engaging in adaptive self-regulation.

Individuals' adaptive self-regulatory efforts should have greater payoffs (in terms of enhancing reputational effectiveness) in jobs defined by three characteristics: task interdependence, ambiguity, and a scarcity of directly provided or spontaneous feedback. Each of these characteristics undermines the efficacy of organizational control mechanisms, and concomitantly increases the importance of self-regulation as a substitute control process.

To the extent that managers operate in interdependent jobs requiring intensive interactions with mutual adjustments to other jobs (Thompson, 1967), the payoff for being active in self-regulation activities such as information search and feedback-seeking should increase. The interdependent nature of their work demands it - constituents beyond the superior become important to performing daily tasks. The heightened needs for coordination increases the importance of these constituents, which in turn, increases the potential payoff of selfregulation activities. Thus:

H13. Managers in jobs high in interdependence will be more active in adaptive self-regulation than managers in jobs low in interdependence. 
Hypothesis 13 is logically consistent with Cheng's (1983) finding that coordination only affected unit performance in units for which highly interdependent tasks were performed. Similarly, we only expect an effectiveness payoff for information search and feedback-seeking when managers are in situations characterized by a high degree of task interdependence.

A second job characteristic is the degree of ambiguity about what managers should be producing in their jobs and how they should go about it. Thompson (1967) labels these as ambiguity in output standards (ends) and in transformation technology (means), respectively. While all managerial jobs are ambiguous to some degree, differences in ambiguity regarding either or both means and ends should affect the payoff for self-regulation. Specifically, collecting information about others' expectations will have more payoff for managers in jobs that do not have objective, measurable output standards or well defined transformation technologies. In highly structured and clear-cut jobs, there is less need for information search about performance expectations and opinions.

H14. Managers in jobs with high task ambiguity will be more active in adaptive self-regulation than managers in jobs with low task ambiguity.

Task ambiguity also implies low task-generated feedback. A third related job contextual factor is indeed the amount of feedback spontaneously provided by the job and others closely involved with the job. Environments differ in the amounts of information available to employees (Herold \& Parsons, 1985). When managers receive a great deal of information and feedback, they will have less of a need to engage in self-regulatory information and feedback seeking on their own (cf. Ashford, 1986). The payoff for active feedback seeking is lower in these feedback-rich jobs than in jobs where little feedback is forthcoming. Thus:

H15. Managers will be more active in seeking feedback when they recelve little spontaneous feedback from the job or from others than when they receive a lot of feedback from these sources.

Several organizational factors also affect the payoffs associated with individual self-regulation efforts. The first organizational factor is the tolerance of the environment; specifically, its tolerance of mediocrity (Ashford, 1989). To follow a biological analogy, all environments exert selection pressuresorganisms that have certain characteristics or that have adopted certain action strategies are "selected" for survival (and thus the importance of maintaining a fit between one's own control system and that of the environment). Environments differ, however, in the strictness of these selection pressures. Slovic, Fischoff, and Lichtenstein (1977, p. 20) argued, for example, that many environments are not structured to "show our limits." Decision makers who recognize that they exist in such an environment are freed from the demand 
of rigorous decision-making. Similarly, organizational environments differ in the extent to which they test individual limits and select individuals for survival based on that assessment. As a concrete example, consider the old and the new AT\&T. As described in Shaw, Fisher, and Randolph (1991), in the past AT\&T employees were generally hired for life, and, according to company lore, mediocre performance was sometimes tolerated. The new AT\&T shifted to an environment of increasing strictness. Poor performers were asked to leave or retire, pay began to be based on merit, and a culture of internal "friendly" competition was fostered. We predict that as the environment more strictly enforces its selection criteria, managers' self-regulation behaviors will also increase. This increase would occur as managers recognize the new importance of (and sudden uncertainty of) survival and success, and associated cost of errors and value of good performance (McAllister, Mitchell, \& Beach, 1979). This discussion suggests the following hypothesis:

H16. Managers will be more active in adaptive self-regulation in an organization where poor performance has high costs than in an organization where mediocrity is tolerated.

The second organizational factor is the degree of hierarchical orientation. In organizations with a strong top-down hierarchical orientation, attaining and maintaining favorable effectiveness reputations with constituencies beyond the superior may be less of a concern. In these settings, the focus of the selfregulation process would be solely on the superior. In a decentralized organization where decision-making generally involves the inputs of lower level organizational members, information- and feedback-seeking from subordinates and peers would be important.

A firm's compensation and control systems may also reflect the degree of hierarchical orientation. In organizations where evaluation of managers is based solely on the opinion of the hierarchical superior, effectiveness opinions by others will be less important. In contrast, if the formal evaluation system and reward decisions require the inputs of peers and subordinates, managers will be more likely to engage in self-regulation processes actively with these constituencies. The following hypothesis captures the effects of hierarchical orientation:

H17a. Managers will focus their adaptive self-regulation efforts more on superiors than on subordinates and peers in organizattons with hierarchical structures.

H17b. Managers will engage in more active self-regulation regarding peers and subordinates in organizations with horizontal or matrix structures than in organizations with hierarchical structures.

H17c. Managers will focus their active self-regulation efforts more on subordinates and peers when the organization values the inputs of these two constituencies in its formal performance appratsal and reward systems than when it does not. 
A third organizational factor is the nature of the communication climate in the organization. Organizations may vary in both the frequency and quality of interpersonal communication (Porter \& Roberts, 1976). The quality of communication may influence effectiveness in performance. For example, O'Reilly and Roberts (1977) found that group effectiveness to be associated with perceived information accuracy and communication openness. In organizations where open communication is encouraged, managers should be more willing to engage in active information- and feedback-seeking. In organizations where there is a perception of low accuracy in the information exchanged between individuals, managers will be less likely to seek information or feedback. Therefore, the following hypothesis is offered:

H18. Managers will be more active in feedback seeking when the organization's communication climate is percelved to be high in openness and accuracy than when tt is perceived to be low in openness and accuracy.

Finally, several organizational processes may also influence the extent to which managers are encouraged or discouraged from engaging in adaptive selfregulation. The first of these is socialization. If an organization specifically and explicitly emphasizes to new employees the importance of attention to multiple constituencies, then these new employees will be more likely to engage in selfregulation (i.e., seeking input on goals and feedback on performance) with a variety of constituencies.

This type of orientation and training would differ from typical managerial training in several important respects. First, it would elevate lateral peers and subordınates to a high status as important constituents in a manager's workworld. Second, it would emphasize the teaching of processes (e.g., standard setting and discrepancy detecting and reducing) rather than the teaching of specific roles to be fulfilled (e.g., Mintzberg's managerial roles). New managers would be taught that there is no universal set of roles to be fulfilled but rather that the relative importance of various roles will depend on their particular constituents. To determine this, they will need to become facile with the discrepancy detection process. Third, it should be constructed to help managers overcome what we perceive to be a potential problem in enacting these three processes effectively: missing standards and constituencies. New managers, in particular, may unknowingly operate on an impoverished set of standards and constituents.

A second process factor is the nature of the norms regarding self-regulation. Norms sanctioning active self-regulation and modeled by top managers may be particularly powerful in encouraging the self-regulation of middle- and lowerlevel managers. Norms sanctioning this behavior can help overcome the focal managers' impression-management concerns associated with asking for information and feedback. For example, Ashford and Cummings (1983) proposed that managers may not want to ask for feedback because such requests expose their needs for this information and such needs may be interpreted as 


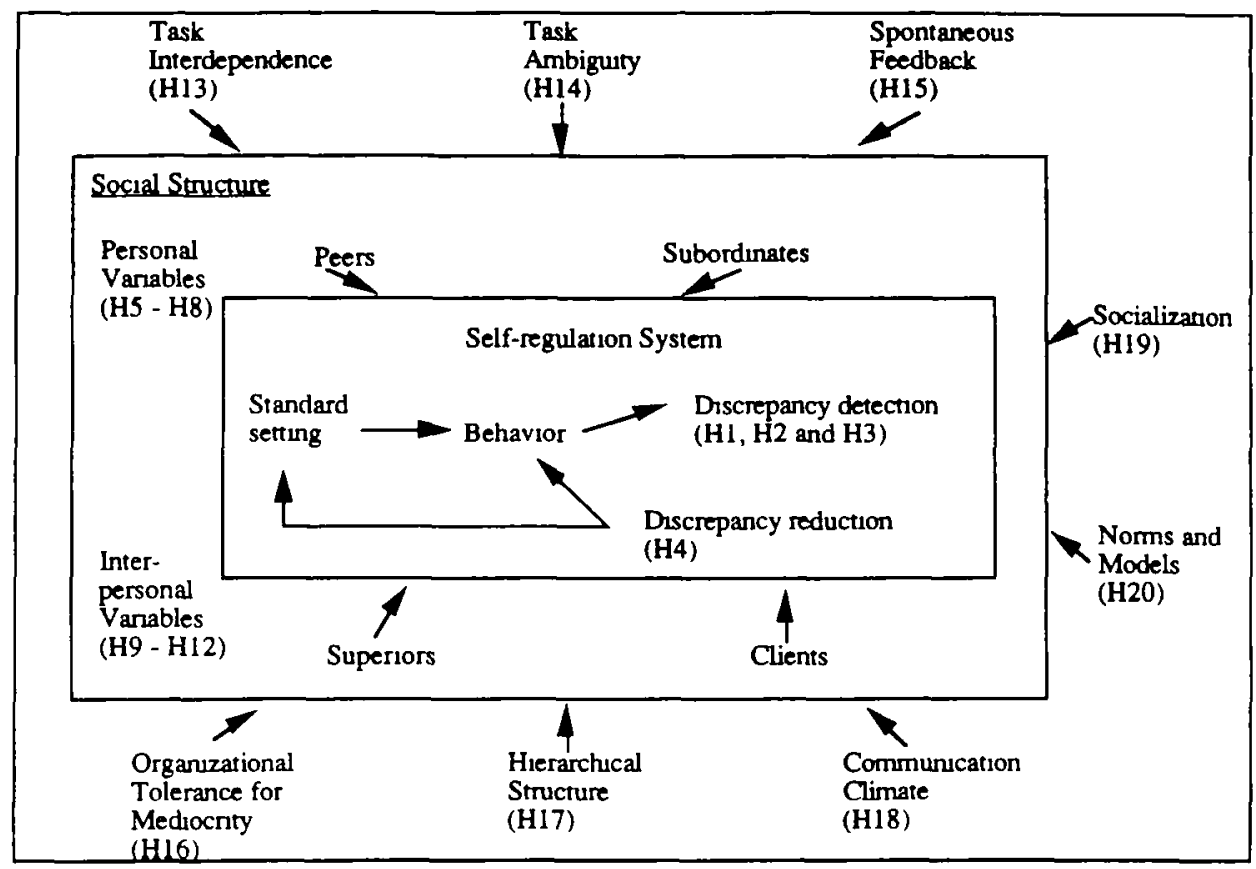

Figure 2. Factors Influencing Adaptive Self-regulation

a sign of weakness by their constituencies. Norms sanctioning information and feedback seeking can help reduce these concerns (Ashford \& Northcraft, 1992). Two additional hypotheses are proposed here to capture the effect of socialization and norms on adaptive self-regulation by managers:

H19. Socialization practices that emphasize the importance of selfregulation and how to self-regulate will be associated with active adaptive self-regulation behaviors by managers.

H20. Explictt norms sanctioning self-regulation and modelling by top managers will be assoctated with active adaptive self-regulation behaviors by managers.

In summary, context variables should play an important role in determining both the prevalence of adaptive self-regulation, the manner in which self-regulation activities is carried out, and its payoff in terms of the reputational effectiveness of managers. Effective managers recognize those contextual conditions where active self-regulation is desired or essential. Ineffective managers may be less sensitive to these contextual cues. Figure 2 shows the self-regulation model including the personal, interpersonal, and contextual factors and associated hypotheses. 


\section{Conclusions and Directions for Research}

We began this article with an observation that the managerial context is becoming more complex and dynamic than before. This reality has many implications for the control and regulation of managerial work. First, it suggests that individual self-regulation efforts may serve as an important substitute for system-level control. In dynamic contexts, organizational-level control systems cannot fully pre-specify appropriate managerial behavior (nor would we want them to in most cases) and thus managers who develop their own systems to control their behavior should perform better than those that do not. This argument suggests the importance of understanding the nature of these individual self-initiated control systems. To this end, we have described the processes involved in self-regulation and tied them to reputational effectiveness, or effectiveness as judged by important constituents in the manager's social structure. Thus, whereas previously the extent of "role fulfillment" was considered a relevant variable in the process stream of managerial effectiveness research, this model specifies the actual processes managers engage in to fulfill varıous roles. Taking effectiveness research to this level of specificity allows us to identify generalizable activities that effective managers may undertake across a variety of settings.

In the model proposed here, we integrate several processes discussed in separate literatures. For example, Ashford and Cummings (1983) and Ashford (1986) have discussed the feedback-seeking process. This model puts that process into a broader context of managerial self-regulation. It also puts feedback seeking in a larger context by tying it to the related processes of information search and discrepancy reduction. Further, the model incorporates ideas in influence strategies, impression management, social cognition, organizational feedback processes, and structure.

In this model, we document where managers may "go astray" in attempting to be effective. For example, some managers might leave out a constituency in their self-management efforts or overemphasize some constituencies relative to others in setting goals. If this is done in a context where these constituencies are important, these managers will not be effective. Alternatively, manager may characteristically seek only confirmatory feedback. In doing so they diminish, unwittingly, their ability to detect and reduce performance discrepancies. Some managers may also be ineffective in discrepancy-reducing attempts. These managers may have the knowledge they need but are unable to translate this knowledge into action. By describing the process of managerial self-regulation in detail, we hope to promote further theoretical efforts directed at specifying how some managers may be contributing to their own ineffectiveness.

The perspective offered here expands the way we might think about selfmanagement or regulation as it occurs in organizations. We argue that to describe managers' self-regulation in organizations we must incorporate the adaptive aspects of the self-management process. Specifically, in contrast to much work in this area (cf. Andrasik \& Heimberg, 1982; Manz \& Sims, 1980), we do not articulate the techniques for explicitly reducing or promoting a 
specific behavior. Rather we draw on control theory for hypotheses regarding the processes in which managers might engage in their attempts to adapt to the demands of their social structure. The resulting model is thus concerned with issues beyond typical self-management concerns. To illustrate, we would argue that it is only when a manager has decided to alter his or her behavior to reduce a particular discrepancy that ideas in self-management become relevant. While recent writings in self-management (Manz, 1986) highlight how individuals lead themselves to focus on more intrinsically motivating tasks, our concern is with how managers manage their relationship with members of their social structure. They may choose goals based on their constituents' input or ignore their input and use influence to sell the goals they have chosen themselves. Thus, the model proposed here complements work in self-management by both presenting a broader self-regulatory framework within which to place specific self-management techniques and by tying these processes to the social and organizational context within which self-regulation occurs.

\section{Future Research}

The proposed model focuses on the major conceptual issues involved in adaptive self-regulation (i.e., its nature and its antecedents). Several theoretical concerns require further elaboration and specification. The first issue is one that also arises in constituency-based models of organizational effectiveness (cf. Keeley, 1984; Zammuto, 1984). That is: How do managers resolve conflicting demands from their various constituency groups? We have taken a first step in addressing this issue by identifying the personal and interpersonal factors that may influence how managers prioritize demands and resolve conflicts between constituency references. Beyond conflicting constituencies, the size of the various constituencies that managers confront also may affect the selfregulation process. Different constituent-management tactics may be demanded in situations where managers have a large group of peers and/or subordinates as opposed to one with a small number.

The second concern is one of terrain. Should a manager be responsive to all constituencies? Specifically, there may be situations when the organization may not want the manager to take constituents' perspectives into account in setting goals and taking actions. For example, a CEO called to turn around a failing organization may not prosper by incorporating the expectations of constituents from within the ill-fated organization. In this case, the CEO is expected to bring new ideas and vision to the organization. Similarly, organizations that attempt to change their cultures by hiring different types of new managers probably do not want those managers to be fully responsive to internal constituent demands when they are on the job. The constituents in this case represent the old culture. These examples suggest that identifying relevant and important constituencies may be an important step in the self-regulation process.

Different constituencies may be important for organizations in different economic, legal, and social contexts (Tsui, 1990). For example, labor unions may be important in the automobile industry while consumer advocates may 
be particular strong in the consumer products industry. A new leader may add some constituencies while dropping others as he/she redirects the organization. $\mathrm{S} /$ he may also be more responsive to some constituencies while decreasing the power of others. For example, deans of many business schools have activated the "business" constituency in the recent years in order to increase support and resources. The relative importance of different constituencies also may vary according to the level and function of the manager. For first line supervisors in a production function, employees and unions may be important constituencies. For middle managers in a matrix structure, peer managers in other functional units may be relatively more important than either superiors or subordinates. Stockholders, regulatory agencies, and consumers are particularly important constituencies for top managers. The current framework has focused primarily on the breadth of the constituency set (as specified in H2) as an important consideration in effective self-regulation. Determining and specifying the composition of different constituency sets and the relative importance of each of these constituencies for different organizations and for different managers within the organizations are important future extension to the self-regulation framework.

Research might consider some different conceptualizations of effectiveness and how they may relate to the self-regulation process. To date, we have operationalized it as the perceived effectiveness of a manager by his or her immediate constituents-superior, subordinates, and peers. One might also measure effectiveness by having a panel of key informants drawn from different parts of a company to rate a sample of managers according to what the rater has heard (reputation) about the manager's effectiveness. This operationalization comes closer to what we generally mean by reputation in politics or the arts. It would be interesting to examine the relationship between a general reputation for effectiveness and the specific manner of self-regulation by managers. It may be that there are quite different processes involved in being viewed as effective by one's superior, subordinates, and peers, on the one hand, and becoming well known in the organization on the other.

Also desirable is further conceptual work and associated empirical research on the effect of self-regulation as described here on other measures of managerial effectiveness such as the performance of the work units managed by the selfregulating managers. Logically, higher performance can be expected of units managed by managers who are more rather than less active in self-regulation. However, the link between the behavior of managers and the performance of their units or organizations is considered to be highly tenuous by some researchers (e.g., Pfeffer, 1977; 1981). It would be useful to identify the conditions when managerial self-regulation will be either strongly or weakly associated with measures of success at both the unit and the organizational level.

Another important research area is that involving management style. The processes required to maintain reputational effectiveness portrayed here occur between the manager and his or her constituents-they are decidedly interpersonal. This portrayal suggests that additional variables may be particularly relevant to subsequent effectiveness research. That is, it is not simply 
becoming active and engaging in these processes that is a primary effectiveness determinant. The manner in which managers go about these processes should be of importance as well. For example, how a manager carries out the processes of discrepancy-detection and reduction may have a significant independent influence on his or her subsequent reputational effectiveness. The issue of how managers can determine and be responsive to the views of their constituents while conveying the impression that they are self-confident and sure of their own agendas is worthy of further research.

A final research area would involve extending some of the adaptive selfregulation hypotheses outlined here to the group level. Recent work has proposed that groups too can be self-managed. Our theory would suggest that this work might pursue the adaptive elements of group self-management as relevant predictors of group effectiveness. Thus our perspective would push group research along the lines of that pursued by Ancona $(1988 ; 1990)$.

\section{Practıcal Implicatıons}

Assuming some level of model validity, we can identify a number of practical implications. First, Hypotheses 16-20 suggest several actions organizations can take to facilitate, improve, or encourage self-regulation. Based on hypothesis 19 concerning socialization practices, we suggest the use of orientation and training to increase the managers' awareness of the importance of self-regulation and impart the skills necessary for engaging in this process. Examples of firms engaged in this kind of orientation and training are American Express and Johnson \& Johnson. The former conducts a training module on the concept of $360 \mathrm{x}$ management to deemphasis a traditionally vertical orientation. The latter has incorporated sessions on lateral relations in their managerial training courses. These examples are consistent with our conceptual arguments concerning the importance of attention to multiple constituencies in the self-regulation process. In such training sessions, the importance of identifying relevant constituencies and methods to determine which constituencies may be more important under what types of organizational conditions could be included as additional topics for discussion. The training might also sensitize managers to the conditions under which adaptive selfregulation is more or less necessary, including the nature of their jobs and the structure of their organizations.

A second practical implication that can be derived from our self-regulation framework is the need to address the impression-management concerns of the focal manager. For example, managers may be reluctant to seek negative feedback for fear of exposing weakness. Organizations can address this concern by encouraging and reinforcing self-regulation behavior through the creation of norms favoring such behaviors and the promotion of role models by top managers. Ashford and Northcraft (1992) have shown that the existence of such a norm lead to greater feedback seeking by individuals in a group setting. Top managers can also model the desired behavior and reward other managers that set such an example. 
Lastly, our theoretical perspective may have implications for the design of organizational control systems. Mechanisms of control include personal supervision, standard operating procedures, compensation systems, planning and goal-setting systems that define performance standards, feedback, evaluation, and measurement. The self-regulation model of managerial effectiveness presented in this study focuses on the planning and feedback components of the cybernetic control model (Flamholtz, Das, \& Tsui, 1985). Thus, self-regulation is not only a substitute for leadership (Manz \& Sims, 1987), but as suggested by Mills (1983), it is also a substitute for other forms of external control that are difficult to create and apply to the ambiguous and ever-changing managerial job. Self-regulation will be more or less important as a substitute control mechanism depending on the technology of the job, the nature of the organizational structure, and the cultural norms of the organization regarding performance and communication. By understanding these contextual factors, control system architects can determine when self-regulation is a necessary and important control mechanism for increasing managerial effectiveness.

Acknowledgment: The authors contributed equally to this research effort. We would liketo thank Craig Pinder, Jim Walsh and the anonymous reviewers for their comments on a previous draft of this manuscript. Thanks also are due to the research colloquia groups at the Tuck School of Business, Dartmouth College and the Fuqua School of Business, Duke University for their advice and guidance early in this research effort.

\section{Notes}

1 A controversy exists regarding whether discrepancies are aversive and whether individuals act to increase or decrease discrepancies Locke and Latham (1990) argue that people set goals (create discrepancies) and move toward them Discrepancy reduction is a byproduct of this movement but discrepancies themselves are not aversive Carver and Scheier (1981) propose that discrepancies are aversive We propose that individuals probably do both-they set goals and are motivated to close the gap between their current state and goal For our purpose, we argue that discrepancies must be managed Whether aversive or not, the fact that there is a discrepancy between what the manager wants and what constituents want suggests that it is in the manager's instrumental interest to identify and to reduce the discrepancy

2 In this case, detection and production serve the same function Each brings about the awareness of the presence of discrepancies

\section{References}

Ancona, D (1988) Beyond task and maintenance Definıng external functions in groups Group and Organization Studies, 13(4) 468-494

(1990) Outward bound Strategies for team survival in an organization Academy' of Management Journal, 33(2) 334-365

Andrasik, F \& Heimberg, J S (1982) Self-management procedures Pp 219-247 in L W Fredrickson (Ed), Handbook of organizallonal behavior management New York Wiley

Ashford, S J (1986) The role of feedback seekıng in individual adaptation A resource perspective Academy of Management Journal, 29 465-487

(1989) Self-assessments in organizations A review and integrative model $\mathrm{Pp}$ 133-174 in B M Staw \& L L Cummings (Eds), Research in organizational behavior, Vol 11 Greenwich, CT JAI

Ashford, S J \& Cummings, L L (1983) Feedback as an individual resource Personal strategies of creating information Organizational Behavior and Human Performance, 32 370-398

(1985) Proactive feedback seeking The instrumental use of the information environment Journal of Occupational Psychology, 58 67-79 
Ashford, S J \& Northcraft, G B (1992) Conveying more (or less) than we realize The role of impressionmanagement in feedback seeking Forthcoming in Organizational Behavior and Human Decision Processes, 53 310-334

Ashford, S J \& Tsuı, A S (1991) Self-regulatıon for managerıal effectiveness The role of active feedbackseekıng Academy of Management Journal, 34(2) 251-280

Bandura, A. (1988) Perceived self-efficacy Exercise of control through self-behef Pp 27.59 in J P Darwalder, M Perrez, \& V Hobı (Eds), Annual series of European research in behavior therapy, Vol 2 Lisse, Netherlands Swets \& Zeitlinger

Bies, R J (1987). The predicament of injustice The management of moral outrage Pp 289-320 in L L Cummings \& B M Staw (Eds), Research in organizational behavior, Vol 9 Greenwich, CT JAI

Blumberg, H H (1972) Communication of interpersonal evaluations Journal of Personality and Social Psychology, 23 157-162

Brickman, P \& Bulman, R (1977) Pleasure and pain in social comparison Pp 149-186 in J M Suls \& R L Miller (Eds), Social comparison processes Washington Hemisphere Publishing Corporation

Brıggs, S R, Cheek, J M , \& Buss, A H (1980) An analysis of the self-monitoring scale Journal of Personalty and Social Psychology, 38 679-686

Buono, A F \& Bowditch, J L (1989) The human side of mergers and acquisitions Managing collisions between people, culture, and organizations San Francisco Jossey-Bass

Cameron, K, Freeman, S J , \& Mishra, A K (1991) Best Practices in white-collar downsızıng Managing contradictions Academy of Management Executive, 5(3) 57-73

Campbell, J P, Dunnette, M D, Lawler, E E III, \& Weıck, K E, Jr (1970) Managerial behavior, performance and effectiveness New York McGraw-Hill Book Company

Campion, M A \& Lord, R G (1982) A control system conceptualızation of the goal-setting and changing process Organizational Behavior and Human Performance, 30 256-287

Carver, C S \& Scheier, M F (1981) Attention and self-regulation A control-theory approach to human behavior New York Springer-Verlag

Chase, $\mathbf{J}$ (1990) The open-book managers Inc (September) 104-113

Cheng, J L (1983) Interdependence and coordination in organızations A role-system analysis Academy. of Management Journal, 26. 156-162

Felson, R B (1980). Communication barners and the reflected appraisalprocess Social Psychology' Quarterly, 43 223-233

Fisher, C D (1979) Transmission of positive and negative feedback to subordinates A laboratory investigation Journal of Applied Psychology, 64 533-540

Fisher, C D \& Gitelson, R (1983) A meta-analysis of the correlates of role conflict and ambiguity Journal of Applied Psychology, 68(2) 320-333

Flamholtz, E G , Das, T K , \& Tsui, A S (1985) Toward an integratıve framework of organızationai control Accounting, Organizations and Soctety, 10(1) 35-50

Gabarro, J J \& Kotter, J P (1980) Managing your boss Harvard Business Review, 58 92-100

Gross, N, Mason, W S , \& McEachern, A W (1958) Explorations in role analysis Studies of the school superintendency role New York Wiley

Herold, D M \& Parsons, C K (1985) Assessing the feedback environment in work organizations Development of the job feedback survey Journal of Appled Psychology. 70 290-306

Hıckson, D J , Hinıngs, C A , Lee, C A , Schneck, R E , \& Pennıngs J M (1971) A strategic contingencies' theory of intraorganizational power Administrative Sciences Quarterly, 18 216-227

House, R J (1971) A path goal theory of leadershıp effectiveness Administrative Science Quarterly, 16 321-339

Hyland, M E (1987) Control theory interpretation of psychological mechanisms of depression Comparison and integration of several theories Psychological Bulletin, 102(1) 109-121

Ilgen, D R, Fisher, C D , \& Taylor, S M (1979) Consequences of individual feedback on behavior in organizations Journal of Applied Psychology, 64 359-371

Ilgen, D R \& Knowlton, W A (1980) Performance attributional effects on feedback from subordinates Organizational Behavior and Human Performance, 25 441-456

Jackson, S E \& Schuler, R S (1985) A meta-analysis and conceptual critique of research of role ambiguity and role conflict in work settings Organizational Behavior and Human Decision Processes, 36 1678

Jaques, E (1961) Equitable pavment New York Wiley

Janis, I \& Mann, L (1977) Decision making New York The Free Press

Jones, E E \& Gerard, H B (1967) Foundanons of social psychology New York Wiley

Kahn, R L, Wolfe, D M, Quinn, R P, Snoek, J D , \& Rosenthal, R A (1964) Organizatıonal siress Studies in role conflict and ambiguty. New York Wiley 
Kanfer, F H (1971) The maintenance of behavior by self-generated stımul and reinforcement Pp 39-59 in A Jacobs \& L B Sachs (Eds), The psychology of private events New York Academic Press

Kanfer, F H \& Karoly, P (1972) Self-control A behavionstic excursion into the lion's den Behavior Therapy, 3 398-416

Keeley, M (1984) Impartiality and participant-ınterest theories of organızational effectiveness Administrative Science Quarterly, 29 1-25

Kenny, D A \& Zaccaro, S J (1983) An estımate of varıance due to tratts in leadership Journal of Applied Psychology, 68(4) 678-685

Kıpnıs, D, Schmıdt, S M , \& Wılkınson, I (1980) Intraorganızatıonal influence tactıcs Explorations in getting one's way Journal of Appled Psychology, 65 440-452

Kotter, J P (1982) What effective general managers really do? Harvard Business Review', (NovemberDecember) 156-167

Larson, J R, Jr (1986) The impact of subordinate behavior on supervisors' delivery of performance feedback Paper presented at the meeting of the Academy of Management, Chicago

Lennox, R \& Wolfe, R (1984) Revision of the self-monitoring scale Journal of Personality and Social Psychology, 46 1349-1364

Locke, E A \& Latham, G P (1990) A theory of goal setting and task performance Englewood Cliffs, NJ Prentıce-Hall

Luthans, F (1988) Successful vs effective real managers Academy of Management Executive, 11(2) 27 132

Luthans, F \& Davis, T (1979) Behavioral self-management (BSM) The missing link in managerial effectuveness Organizational Dynamics, $8 \quad 42-60$

Mahoney, M J \& Arnkoff, D B (1978) Cognitive and self-control theraptes Pp 689-722 in S C Garfield \& A E Borgin (Eds), Handbook of psychotherapy and therapy change New York Wiley

Manz, C C (1986) Self-leadership Toward an expanded theory of self-influence processes in organizations Academy of Management Review, II 585-600

Manz, C C \& Sims, H P, Jr (1980) Self-management as a substitute for leadership A social learning theory perspective Academy of Management Review, 5 361-367

Manz, C C \& Sims, H P (1987) Leading workers to lead themselves The external leadershıp of selfmanaging work teams Administrattve Sctences Quarterly. 32(1) 106-128

March, J G \& Simon, H A (1958 Organizatıons New York Wiley

McAllister, D, Mitchell, T R, \& Beach, L R (1979) The contingency model for selection of decision strategies An impirical test of the effects of significance, accountability, and reversibility Organizanonal Behavior and Human Performance, 24 228-244

Miller, D T (1976) Ego involvement and attributions for success and fallure Journal of Personality and Social Psychology, 34 901-906

Mills, P K (1983) Self-management Its control and relationshıp to other organizational properties Academy of Management Revtew, 8 445-453

Mintzberg, H , Raisinghanı, D , \& Theoret, A (1976) The structure of "unstructured" decision processes Administrative Science Quarterly, 21 246-276

Mintzberg, H (1973) The nature of managerial work New York Harper \& Row

Moos, R H \& Bullings, A G (1982) Conceptualizing and measunng coping resources and processes $\mathrm{Pp}$ 212-230 in L Goldberger \& S Breznitz (Eds), Handbook of stress New York The Free Press

Morse, J \& Wagner, F (1978) Measuring the process of managerıal effectiveness Academy of Management Journal, 21 23-35

Nutt, P C (1984) Types of organizational decision processes Administrative Science Quarterly, 29(3) 414-450

O'Reilly, C A, III \& Anderson, J (1980) Trust and the communication of performance appraisal information The effect of feedback on performance and satisfaction Human Communication Research, 6(4) 290-298

O'Reilly, C A, III \& Roberts, K H (1977) Task group structure, communication, and effectiveness in three organizations Journal of Applied Psychology, 62(6) 674-681

Pfeffer, J (1977) The ambiguty of leadership Academy of Management Review, 2 104-112

(1981) Management as symbolic action The creation and maintenance of organizational paradigms Pp 1-52 in L L Cummings \& B M Staw (Eds), Research in organizational behavior, Vol 3 Greenwich, CT JAI

Porter, L W \& Roberts, K H (1976) Communication in organizations Pp 1553-1589 in M Dunnette (Ed), Handbook of industrial and organizational psychology Chicago Rand McNally

Powers, W T (1973) Behavior The control of perception Chicago Aldine

Salancık, G R, Calder, B J, Rowland, K M, Leblebıcı, H, \& Conway, M (1975) Leadershıp as an outcome of social structure and process A multidimensional analysis Pp $81-101$ in $\mathrm{J}$ G Hunt \& E E Larson (Eds), Leadership frontıers Columbus, $\mathrm{OH}$ Kent University Press 
Shaw, J B , Fisher, C D , \& Randolph, W A (1991) From maternalism to accountabilty. The changing cultures of MA Bell and Mother Russia Academy of Management Executive, 5(1) 7-20

Slocum, J W \& Sims, H P (1977) The leader as manager of reinforcement contingencies An empincal example and a model Pp 121-139 in J G Hunt \& L L Larson (Eds), Leadership The cutting edge Carbondale, IL Southern Illınois University Press

Slovic, P , Fischoff, B , \& Lichtenstein, S (1977) Behavioral decision theory Annual Review of Psychology. $28 \quad 1-9$

Snyder, M (1979) Self-monitoring processes Pp 86-124 in L Berkowitz (Ed), Advances in experimental social psychology, Vol 12 New York Academic Press

Snyder, M \& Gangestad, S (1986) On the nature of self-monitoring Matters of assessment, matters of valıdity Journal of Personality and Social Psychology, 5I(1) 125-139

Staw, B M \& Ross, R (1980). Commitment in an experimenting society A study of the attribution of leadership from administrative scenanos Journal of Appled Psychology, 65 249-260

Stewart, R (1979) Managenal agendas Reactive or proactive Organizational Dynamics, (Autumn) 3447

(1982) A model for understanding managerial jobs and behavior Academy of Management Review, 7 7-13

Taylor, M S, Fisher, C O, \& Ilgen, D R (1984) Individuals' reactions to performance feedback in organizations A control theory perspective Pp 81-124 in G Ferris \& K Rowland (Eds), Research in personnel and human resources management, Vol 2 Greenwich, CT JAI

Tesser, A \& Rosen, S (1975) The reluctance to transmit bad news Pp 194-232 in L Berkowitz (Ed). Advances in experimental social psychology, Vol 8 New York Academic Press

Tetlock, P E \& Manstead, A (1985) Impression management versus intrapsychic explanations in social psychology A useful dichotomy Psychological Review, 92 59-77

Thomas, K W (1976) Conflict and conflict management Pp 880-904 in M D Dunnette (Ed), Handbook of industrial and organizatıonal psychology' Chicago Rand McNally

Thompson, J D (1967) Organizanions in action New York McGraw-Hill

Trope, Y (1975) Seekıng information about one's own ability as a determinant of choice among tasks Journal of Personality and Social Psychology, 32 1004-1013

Tsui, A S (1984a) A multiple-constituency framework of managerial reputational effectiveness Pp 2844 in J Hunt, D Hoskıng, C Schnesheım, \& R Stewart (Eds), Leaders and managers Internatıonal perspectives on managerial behavior and leadership New York Pergamon.

(1984b) A role set analysis of managerial reputation Organizational Behavior and Human Performance, $36 \quad 64-96$

(1990) A multıple-constituency model of effectiveness An empincal examination at the human resource subunit level Administrative Science Quarterly. 35 458-483

Willerman, B , Lewitt, D , \& Tellegen, A (1960) Seeking and avoıdıng self-evaluation by workıng individually or in groups Pp 42-64 in D Wilner (Ed ), Decision, values and groups New York Pergamon Press

Wood, R \& Bandura, A (1989) Social cognitive theory of organizational management Academy of Management Review, 14(3) 361-384

Zammuto, R F (1984) A comparison of multiple constituency models of organizational effectiveness Academy of Management Review, 9 606-616

Zuckerman, M, Brown, R H, Fox, G A, Lathın, D R, \& Minasıan, A J (1979) Determinants of information seeking behavior Journal of Research in Personality, 13 161-174 